\title{
Alcances terapêuticos e matriciais: uma experiência de grupo de saúde mental na atenção básica' ${ }^{1}$
}

\author{
Therapeutic and matrix reaches: an experience of a \\ mental health group in primary care
}

\author{
Ámbitos terapéuticos y matriciales: una experiencia \\ grupal de salud mental en la atención primaria
}

\section{Yanna Cangussu' ${ }^{1}$ (D) Lidiane Guedes ${ }^{2}$ (D)}

1Autora para correspondência. Escola Bahiana de Medicina e Saúde Pública (Salvador). Bahia, Brasil. yanna.cangussu@gmail.com ${ }^{2}$ Universidade Federal do Recôncavo da Bahia (Santo Antônio de Jesus). Bahia, Brasil. guedes.lidiane@gmail.com

\begin{abstract}
RESUMO | INTRODUÇÃO: A saúde mental ganha um outro lugar no sistema de cuidado integral à saúde a partir do SUS. A Atenção Básica passa a integrar a RAPS desde a Portaria 3.088, de 23 de dezembro de 2011, tornando-se corresponsável por este cuidado. Na prática essa mudança ocorre de forma progressiva e encontra barreiras, principalmente quanto a formação dos profissionais e alguns estigmas enraizados. Diante disso, destaca-se a importância de ações que visem promover a saúde mental neste contexto. OBJETIVO: Refletir acerca dos desafios e potencialidades da AB frente as demandas de SM e do matriciamento entre os profissionais de saúde, através do relato da experiência de um grupo de cuidado em SM, sob o ponto de vista de uma psicóloga da Residência Multiprofissional de Saúde da Família (FESF-Fiocruz). MÉTODO: Trata-se de um relato de experiência, de caráter qualitativo, sobre um grupo de cuidado em SM realizado em uma USF em Lauro de Freitas (BA). RESULTADOS E DISCUSSÕES: O grupo foi desenvolvido de forma interdisciplinar e com participação social. Visou ser terapêutico, abrindo-se para a escuta e fortalecimento de vínculos, além de ser um espaço de matriciamento. CONSIDERAÇÕES FINAIS: A AB é um serviço fundamental na estruturação da RAPS, porém ainda está num processo de se reinventar neste papel. O grupo demonstra como pode ser um desafio ir além da lógica biomédica, se propor a superar estigmas, criar novas possibilidades de cuidado em saúde, e se permitir ser afetado pela experiência, mas também como pode ser transformador para a saúde mental e formação dos envolvidos.
\end{abstract}

PALAVRAS-CHAVE: Atenção básica. Saúde mental. Grupo. Matriciamento.

ABSTRACT | INTRODUCTION: Mental health gains another place in the health care system from the SUS. Primary Care has become part of the RAPS since Ordinance 3088 (2011), becoming co-responsible for this Care. In practice, this change occurs progressively and encounters barriers, especially regarding the training of professionals and some ingrained stigmas. Therefore, the importance of actions aimed at promoting mental health in this context is highlighted. OBJECTIVE: to reflect on the challenges and potential of $A B$ in the face of the demands of $\mathrm{MH}$ and the matrix support among health professionals, through the report of the experience of a care group in $\mathrm{MH}$, from the point of view of a psychologist of the Multiprofessional Health Residency of the Family (FESF-Fiocruz). METHOD: This is an experience report, of a qualitative nature, about an MS care group carried out at a USF in Lauro de Freitas (BA). RESULTS AND DISCUSSIONS: The group was developed interdisciplinary and with social participation. It aimed to be therapeutic, opening itself to listening and strengthening bonds, in addition to being a space for matrix support. FINAL CONSIDERATIONS: AB is a fundamental service in the structuring of RAPS, but it is still in the process of reinventing itself in this role. The group demonstrates how challenging it can be to go beyond the biomedical logic, propose to overcome stigmas, create new possibilities for health care, and allow oneself to be affected by the experience, but also how it can be transformative for mental health and the training of those involved.

KEYWORDS: Primary care. Mental health. Group. Matrix support.

\footnotetext{
'Este artigo foi apresentado como Trabalho de Conclusão de Especialização (TCE) para título de especialista na Pós-Graduação em Saúde Mental e Atenção Básica pela Escola Bahiana de Medicina e Saúde Pública. 
RESUMEN | INTRODUCCIÓN: La salud mental gana otro lugar en el sistema integral de atención a la salud a partir del SUS. La Atención Primaria pasa a formar parte del RAPS a partir de la Ordenanza 3088 (2011), pasando a ser corresponsable de esta atención. En la práctica, este cambio se da de forma progresiva y encuentra barreras, especialmente en lo que se refiere a la formación de los profesionales y algunos estigmas arraigados. Por lo tanto, se destaca la importancia de las acciones dirigidas a la promoción de la salud mental en este contexto. OBJETIVo: Reflexionar sobre los desafíos y potencialidades de la AB frente a las demandas de la HM y el apoyo matricial entre los profesionales de la salud, a través del relato de la experiencia de un grupo de atención en la HM, en la óptica de una psicóloga del Residencia Multiprofesional en Salud de la Familia (FESF-Fiocruz). MÉTODO: Se trata de un relato de experiencia, de carácter cualitativo, sobre un grupo de atención a la EM realizado en una USF de Lauro de Freitas (BA). RESULTADOS Y DISCUSIÓN: El grupo se desarrolló de forma interdisciplinaria y con participación social. Pretendió ser terapéutico, abriéndose a la escucha y fortaleciendo vínculos, además de ser un espacio de apoyo matricial. CONSIDERACIONES FINALES: AB es un servicio fundamental en la estructuración de RAPS, pero aún está en proceso de reinventarse en este rol. El grupo demuestra cuán desafiante puede ser ir más allá de la lógica biomédica, proponer superar estigmas, crear nuevas posibilidades para el cuidado de la salud y dejarse afectar por la experiencia, pero también cómo puede ser transformadora para la salud mental y la formación de los implicados.

PALABRAS CLAVE: Atención primaria. Salud mental. Grupo. Matriciamento.

\section{Introdução}

Revolucionário é um adjetivo que caracteriza fortemente o Sistema Único de Saúde (SUS) brasileiro, por trazer uma perspectiva sobre o cuidado diferente da tradicional biologicista e meramente curativista. A partir da Reforma Sanitária e da Reforma Psiquiátrica (RP) a mudança no que se refere à saúde foi estrutural, reafirmandoa como direito, e abrindo espaço para a participação e controle social (Nogueira \& Brito, 2017).

A RP, tendo como protagonistas os trabalhadores da saúde mental (SM), os usuários e seus familiares, tinha como objetivo primordial a desconstrução do paradigma manicomial (Ramos \& Pio, 2010). De acordo com Paulo Amarante (1995), o movimento partiu da indignação frente as práticas manicomiais que se embasavam na psiquiatria clássica. Essas instituições que deveriam promover a saúde, acabavam por cronificar os casos e segregar os sujeitos, além de toda violência institucional que alarmava a sociedade. A nova perspectiva trazia a ideia de estender o cuidado à espaços públicos, promover a reinserção social, a humanização e a garantia de direitos. A partir da criação do SUS, a SM passa a incorporar o sistema de cuidado integral, e o modelo de assistência voltase à promoção da saúde, tornando seu objeto central o sujeito biopsicossocial, e não mais a doença. É somente em 2001 que o movimento iniciado na década de 80 conquista o sancionamento da Lei n. 10.216, que garante os direitos das pessoas com transtornos mentais e redireciona todo o modelo assistencial (Almeida et al., 2020).

Nesse contexto a Atenção Básica (AB) se destaca por suas principais atribuições estarem voltadas para promoção da saúde e prevenção de agravos, envolvendo ações de diagnóstico e tratamento, reabilitação, redução de danos e a manutenção da saúde (Ministério da Saúde, 2012). Assim ela assume um papel articulador entre os serviços da Rede de Atenção à Saúde (RAS), sendo base para os níveis de atenção secundário e terciário. Na forma em que se estrutura, territorializada e como principal porta de entrada, a AB tem a possibilidade de conhecer a população daquele território e suas necessidades reais, portanto é nisso que suas ações devem estar pautadas, e tomando como estratégia o uso de tecnologias leves e leves duras (Cangussu, 2020).

Considerando "tecnologias" os recursos materiais e imateriais utilizados para produzir ações transformadoras da natureza (M. M. S. Silva et al., 2015), podemos definir assim tecnologias leves como àquelas relacionadas a produção de vínculo, acolhimento e gestão do processo de trabalho, com destaque para a alta densidade relacional entre trabalhador e usuário. Por sua vez, as leveduras dizem respeito aos saberes estruturados de cada área. Juntas elas dão base ao cuidado na $A B$, sem, no entanto, excluir as tecnologias duras relacionadas a equipamentos tecnológicos, normas e estruturas organizacionais (M. M. S. Silva et al., 2015). Essas ações devem considerar o sujeito como singular, integral e dotado de autonomia, além de compreender que os determinantes sociais de saúde interferem diretamente nas condições de saúde da população (Ministério da Saúde, 2012). Para que toda essa complexidade seja possível é importante que seja um trabalho realizado a partir a corresponsabilização dos serviços de saúde, da atuação em equipes multiprofissionais e com a participação popular.

Entre os usuários acolhidos na $A B$, se incluem aqueles em sofrimento psíquico e que devem encontrar nela um local de cuidado, já que a partir da Portaria $n^{\circ} 3.088$, de 23 de dezembro de 2011, que institui a Rede de 
Atenção Psicossocial (RAPS), a AB se torna corresponsável como parte integrante desta rede. Ramos \& Pio (2010) concordam com a visão de Merhy (M. .M S.M Silva et al., 2015) sobre o cuidado, alocando este conceito como o verdadeiro objeto da saúde, crucial para qualquer intenção de cura, promoção e proteção da saúde. A produção de cuidado é vista aqui como algo dinâmico e realizada por todos os sujeitos envolvidos nas singularidades das relações e das coletividades. Isso não se restringe aos profissionais de saúde, no entanto espera-se que todo profissional de saúde seja um promotor de cuidado capacitado para atuar com tecnologias leves.

A AB é um serviço estratégico nesse sentido, já que se volta para uma aproximação da população e de cada sujeito com suas diversas histórias, incluindo aquelas que tiveram repercussões mais notáveis na saúde mental (Ministério da Saúde, 2013). De acordo com Ramos \& Pio (2010, p. 216):

Todo problema de saúde é também - e sempre mental, e que toda saúde mental é também - e sempre - produção de saúde, nesse sentido, será sempre importante e necessária a articulação da saúde mental com a atenção básica à saúde.

Entre as formas de atuação possíveis da $A B$ frente a SM, estão as de: acolhimento e fortalecimento de vínculo, a escuta e promoção de reinserção social, redução de danos, além de atividades terapêuticas e de lazer, o cuidado com a saúde geral, realização de projetos terapêuticos singulares e articulação do cuidado entre os serviços da RAPS. Acontece que diante de tantas mudanças na lógica de cuidado, é comum encontrarmos profissionais que se sentem inseguros, com dúvidas, receios, ou interesse em se qualificar para melhor atuarem nesses casos, e é a partir disso que surge a proposta do apoio matricial (Cangussu, 2020).

O matriciamento é uma estratégia pedagógica e terapêutica, que visa a promoção de um cuidado compartilhado no qual além da ação de saúde em prol do usuário, os profissionais têm a oportunidade de se qualificarem, isto é, de aprenderem através da troca de saberes uns com os outros (Chiaverini, 2011). Este dispositivo tem grandes potencialidades no que se refere à $S M$ na $A B$, ele pode acontecer tanto de modo intersetorial, entre diversos serviços da RAPS e da RAS, quanto entre as equipes da $A B$ e o Núcleo Ampliado de Saúde da Família (NASF).

A Saúde da Família (SF) é a principal estratégia do SUS para a consolidação da $A B$, tendo em vista a produção de uma atenção mais integral, equânime e contínua, segundo a Portaria $n^{\circ} 2.436$, de 21 de setembro de 2017. O trabalho nesta estratégia é realizado por equipes multiprofissionais, incluindo aí equipes mínimas (eSF) constituídas por médico, enfermeiro e técnico ou auxiliar de enfermagem, dentistas, auxiliar ou técnico de saúde bucal e agente comunitário de saúde ou de endemias; e o NASF.

De acordo com a Portaria $n^{\circ} 2.436$, de 21 de setembro de 2017 e a Política Nacional de Atenção (PNAB), o NASF é constituído por uma equipe multiprofissional e interdisciplinar com categorias profissionais complementares às eSF. Suas especialidades podem variar de acordo com as demandas de cada território e suas ações devem se basear nas necessidades da população e nas dificuldades dos profissionais da AB. Ele deve, portanto, trabalhar numa relação de horizontalidade com os outros profissionais, dandoIhes suporte clínico, sanitário e pedagógico, em prol da longitudinalidade do cuidado. O compartilhamento de saberes, de responsabilidades, a articulação de redes e coletividades são algumas de suas atribuições, como declara a Portaria n 2.436 (2017). O NASF tem o intuito de ampliar a resolutividade da $\mathrm{SF}$, corresponsabilizando-se pelo cuidado e reduzindo os encaminhamentos para atenção especializada (Klein \& d'Oliveira, 2017).

Desde a sua criação pelo Ministério da Saúde (MS) em 2008 o NASF vem sofrendo modificações significativas que ameaçam inclusive sua função de apoio matricial e abre espaço para manutenção de uma lógica mais ambulatorial, oposta à transdisciplinaridade (Melo et al., 2018). Foi em 2019 que ele sofreu seu maior impacto, pois, a partir do programa Previne Brasil, nos deparamos com uma mudança radical no modelo de financiamento da $A B$ no SUS. O repasse dos recursos federais para municípios que costumava ser baseado no número de equipes, incluindo aí equipes de Saúde da Família (eSF) e NASF cadastradas, passa a ser agora por número de usuários cadastrados, e por indicadores de desempenho das equipes (indicadores baseados numa lógica médico centrada e que 
não dão conta de dimensionar a atuação de muitas profissões do NASF). Considerando que as eSF são o mínimo necessário para existir um trabalho de uma Unidade de Saúde da Família (USF), a existência dessas não foi impactada, porém o NASF passa agora a não ter garantias de sua manutenção e nenhum estímulo do MS para a lógica do matriciamento. Fica a cargo dos gestores locais, diante da perda do principal financiador do NASF (o MS), escolher pela manutenção desses profissionais e o modo como eles devem atuar. Isso caracteriza o fim da política nacional do NASF-AB enquanto estratégia, e culminou no fim de diversas equipes, demissão de milhares de profissionais, sobrecargas de eSF e desassistência dos usuários em sua integralidade (Reis \& Meneses, 2020). Fica a questão: será que a nossa saúde merece ter apenas o mínimo necessário para um funcionamento de um serviço? Prefiro pensar que não, afinal toda lógica do SUS pressupõe um trabalho multiprofissional ampliado e integrado, e com uma qualificação contínua, para assim poder tentar lidar com toda a complexidade da vida humana numa população tão grande e múltipla como a do Brasil.

É a partir desse contexto que se torna importante conhecer os trabalhos e potencialidades do NASF frente à saúde e especificamente a SM. Esse artigo, portanto, aborda a experiência de criação/desenvolvimento de um grupo de cuidado em saúde mental realizado em uma USF em Lauro de Freitas - Bahia (BA), sob o ponto de vista de uma psicóloga do NASF. O grupo em questão foi desenvolvido por uma eSF com duas psicólogas(os) do NASF, e teve o apoio também de outros profissionais de equipes mínimas e NASF, tanto nas discussões de planejamento quanto na divulgação, além de ativa participação da comunidade.

Cabe destacar que esta USF tinha a particularidade de receber o programa de Residência Multiprofissional em Saúde da Família e a Residência em Medicina de Família e Comunidade da Fundação Estatal Saúde da Família (FESF) em parceria com a Fundação Oswaldo Cruz (Fiocruz). O território adstrito apresentava uma alta demanda de cuidado em SM e havia uma expectativa de que as (os) psicólogas (os) assumissem um acompanhamento clínico ambulatorial, característico em uma sobrecarga da categoria, bem como uma carência de espaços de matriciamento e promoção de cuidados integrais em saúde. A partir disso surge a ideia deste grupo como um meio de potencializar o acolhimento desses usuários e a corresponsabilização da $A B$ com seus cuidados, através do apoio matricial. Este seria um espaço de trocas entre profissionais e entre profissionais e usuários, de forma a estreitar vínculos, prevenir agravos, promover saúde e crescimento profissional.

Mesmo após anos de RP, o campo da SM ainda é marcado por lutas para garantir e reconhecer seu lugar de cuidado em muitos serviços de saúde, o que é agravado pelas formações de muitos profissionais da $A B$ que reproduzem um padrão hegemônico biologicista e reducionista, não os capacitando para acoIherem esse público. A partir disso, este trabalho tem o objetivo de refletir acerca dos desafios e potencialidades da $A B$ frente as demandas SM e do matriciamento entre os profissionais de saúde, através do relato da experiência de um grupo de cuidado em SM, sob o ponto de vista de uma psicóloga da Residência Multiprofissional de Saúde da Família (FESF-Fiocruz).

\section{Metodologia}

Este é um estudo de caráter qualitativo, considerando que visa se aprofundar em determinado contexto para que se possam tecer reflexões. Trata-se de um relato de experiência de um grupo de cuidado em SM que foi desenvolvido em uma USF de Lauro de Freitas (BA) em 2018, sob o ponto de vista de uma psicóloga residente. Este tipo de trabalho se propõe a contribuir para estudos de uma determinada área a partir do que pode ser aprendido com uma experiência específica (Gerhardt \& Silveira, 2009). Para isso, buscouse preservar o compromisso ético com as pessoas envolvidas na experiência, principalmente quanto ao sigilo de identidades e informações pessoais.

Vivenciar essa jornada de escrita foi um ato de reviver em memória um processo que me transformou como profissional e como pessoa, e para isso foi utilizado o recurso de diário de campo. O diário é uma ferramenta de produção de saber que nos possibilita fazer uma análise da experiência, a partir do registro do que acontece no cotidiano. A escrita é feita com base no campo, e também produz atravessamentos nesse campo. Sua análise pode gerar incômodos, ranhuras e, portanto, deslocamentos de uma ordem instituída e cristalizada, e abertura para a emergência de pensamentos outros, afetações e criações, como aborda Lourau (Nascimento \& Lemos, 2020). 
Lauro de Freitas é uma cidade da Bahia que se estende por $57,7 \mathrm{~km}^{2}$ e contava com 163.449 habitantes no último censo do Instituto Brasileiro de Geografia e Estatística (IBGE) em 2010, com a população estimada em 2021 de 204.669 pessoas (Instituto Brasileiro de Geografia e Estatística). O município vem ampliando sua cobertura da $A B$, sendo que em 2019 atingiram o marco de $75 \%$ de áreas cobertas por USF's, segundo Reyner (05 de agosto, 2019).

Neste caso, a USF tinha a particularidade de receber o programa de Residência Multiprofissional em Saúde da Família e a Residência em Medicina de Família e Comunidade da Fundação Estatal Saúde da Família (FESF) em parceria com a Fundação Oswaldo Cruz (Fiocruz). O programa de Residências Multiprofissionais foi criado pela Lei $n^{\circ} 11.129$ de 2005 com o intuito de viabilizar a inserção e qualificação de jovens profissionais de saúde no mercado de trabalho, e mais especificamente nas áreas demandadas pelo SUS. Elas constituem um modelo de ensino/aprendizagem, com caráter de pós-graduação lato sensu, através das quais os jovens profissionais podem se qualificar enquanto estão inseridos na prática do serviço, contando com um apoio de supervisão docente assistencial, como cita a Lei ${ }^{\circ}$ 11.129, de 30 de junho de 2005.

Esse programa de Residência tinha duração de 2 anos, sendo que no primeiro ano (R1) os residentes assumem o serviço da USF, e no segundo ano (R2) participam de diferentes estágios em outros serviços de saúde da rede, em articulação com a AB. O referido grupo, nomeado de Bem Viver, foi iniciado no meio do primeiro ano dos residentes, e teve duração de 6 meses. A dissolução do grupo ocorreu no final do R1 do meu grupo de profissionais residentes, e isso coincidiu também com outras questões externas que impactaram na saída da residência do município. Este fato acabou limitando a continuidade da proposta e, portanto, maior aprofundamento do estudo.

A USF em questão constava de 5 equipes mínimas e uma equipe de NASF que cobria apenas seu território. Entre os profissionais existiam aqueles que eram membros da residência ou do corpo pedagógico desta, e servidores públicos.
A ideia do grupo foi elaborada através de um diálogo entre duas psicólogas(os) do NASF, em conjunto com uma eSF diante da análise da alta demanda de cuidado em SM no território. Estes foram também os profissionais responsáveis pelo desenvolvimento do grupo: duas psicólogas(os) e uma enfermeira (residentes), um médico (funcionário do município e preceptor da Residência em Medicina de Família e Comunidade) e uma ACS. A equipe tinha mais dois ACS que preferiram não se envolver.

Durante o processo de planejamento o projeto foi discutido como pauta em reuniões de unidade com todos da USF, e com preceptores e apoiadores do programa de residência em outros espaços pedagógicos. O NASF, alguns outros residentes e os ACS apoiaram também no planejamento, trazendo suas visões nas reuniões de unidade e reuniões de NASF, e se disponibilizando a participar em atividades especificas quando solicitados (ex. divulgação). $\mathrm{Na}$ USF já ocorriam reuniões de matriciamento em SM com a participação de psicólogo do Centro de Atenção Psicossocial de álcool e outras drogas (CAPS ad) e profissionais do Consultório de Rua, que acabaram contribuindo com suas reflexões sobre o planejamento. Apesar da RAPS do território trabalhar com o sistema de referência e contrarreferência, viu-se neste grupo a possibilidade de ampliar a corresponsabilização da $A B$ com a SM, e a qualificação dos profissionais a partir do matriciamento. Quando identificadas demandas com perfis para outros serviços na rede, os pacientes eram encaminhados, porém isso não impossibilitava que dessem continuidade aos encontros.

A equipe responsável já costumava realizar reuniões semanais, e nelas foi incluído um tempo destinado para o planejamento do grupo, incluindo sugestões da comunidade. Ao final de cada grupo também era feito um momento de avaliação do dia, tanto com os usuários, quanto exclusivamente com os profissionais, com discussões matriciais. Dessa forma o desenvolvimento do grupo se deu de maneira dinâmica e participativa.

De início foi elaborado um projeto que definia algumas especificidades: seria um grupo de cuidado em 
saúde mental, no qual as pessoas poderiam falar de suas angústias e serem escutadas, poderiam receber apoio, formar vínculos e identificações, além dos profissionais poderem aprender com a prática e com as trocas. Ele era aberto para todos da comunidade que estivessem passando por questões de sofrimento psíquico, porém acontecia em um consultório fechado, com destaque para a importância do sigilo dos assuntos ali abordados. Os responsáveis da eSF deveriam estar sempre presentes como meio de fortalecer o vínculo, porém as(os) psicólogas(os) iriam se revezar para estar sempre uma(o) presente nos grupos, como meio de facilitar o manejo e o apoio matricial, assim como para contemplar a agenda dinâmica do NASF.

Com relação ao público-alvo, os ACS identificaram possíveis usuários com perfil para ingressar no grupo, e realizaram comigo e com a enfermeira da equipe, visitas domiciliares no intuito de estreitar vínculos, apresentar a proposta e convidá-los para o grupo. Além disso, outros profissionais de saúde e as(os) próprias(os) psicólogas (os) faziam o convite quando identificavam a demanda em seus atendimentos. Aos poucos o grupo foi ficando conhecido, e os próprios usuários passaram a convidar outros. Assim, tinham livre acesso à recepção da USF, onde se identificavam e eram orientados quanto a participação.

O grupo ocorria uma vez por semana. Nas segundas feiras era colocado uma placa no consultório onde ocorria, e tinha duração média de 1 hora e meia. Era sempre divido em 3 etapas: 1 . Momento de apresentação se houvessem novos participantes, onde podíamos confirmar a demanda e o perfil (se necessário depois poderia ser discutidas outras estratégias de cuidado para casa caso); 2 . Atividade principal planejada para cada dia; 3. Despedida com música tocada no violão pelo médico da equipe, e cantada por todos. Assim nascia o Bem Viver.

\section{Resultados e Discussões}

\section{0 início do percurso}

Confesso que o processo de residência em si já é um desafio inenarrável, mas neste caso se destaca mais uma particularidade: nós éramos o primeiro grupo de psicólogas (os) a participar desta residência. Havia uma expectativa sobre nós desde o dia de nossas matrículas, devido à alta demanda de cuidado em saúde mental apresentada pelo território e profissionais. Ao mesmo tempo em que fiquei lisonjeada de ser desejada neste local, me vieram também muitas dúvidas: qual era mesmo nosso papel na $A B$ ? Como era o trabalho de um NASF?

O NASF é uma equipe multiprofissional com diferentes categorias da área da saúde e que devem trabalhar em parceria com os profissionais das eSF. Desde a sua criação pela Portaria $n^{\circ} 154$, de 24 de janeiro de 2008, a proposta foi de um trabalho integrado, compartilhando os diferentes saberes e se corresponssabilizando pelo cuidado, como um meio de ampliar o trabalho das equipes da $A B$, rever a prática de encaminhamentos e potencializar as estratégias de cuidado longitudinal. Portanto, o NASF não deve funcionar como porta de entrada do sistema, e seu trabalho vai se delinear de acordo com as demandas apresentadas pelo território e pelas dificuldades apresentadas pelos profissionais das eSF, de maneira a apoiá-los, como afirma a Portaria $\underline{n^{\circ} 154}$, de 24 de janeiro de 2008. Não se trata de um serviço de especialidades da $A B$, pelo contrário, segue-se a lógica de um trabalho matricial, considerando o matriciamento como um modo de produzir saúde através da construção compartilhada do trabalho e com espaços de trocas pedagógico-terapêuticas entre os profissionais (Chiaverini, 2011).

Entre as dificuldades apresentadas pelos profissionais no contexto deste relato, a de lidar com casos de saúde mental se destacava. Inicialmente prevaleceu a prática de encaminhamentos, havia certa expectativa de que a psicologia assumisse sozinha a frente de casos de SM. O Guia Prático de Matriciamento em Saúde Mental, pelo Ministério da Saúde, destaca inclusive que um dos motivos envolvido nesta insegurança pode ser o fato de algumas formações em saúde não se aprofundarem nos estudos da saúde mental, especialmente as mais biologicistas. Além disso, existe a possibilidade de os profissionais só terem convivido com pacientes de saúde mental em contextos hospitalares e em crise, o que incentiva a criação de alguns estigmas (Chiaverini, 2011). A loucura em si já carrega muitos estigmas. 
Almeida et al. (2020) concordam com essa visão sobre as dificuldades desses profissionais poderem se dá, muitas vezes, por sentimentos de medo das reações dos pacientes com transtornos mentais, ou por falta de conhecimento sobre um tema tão complexo que é a SM (Almeida et al., 2020). Também é comum entre eles o sentimento de frustração e impotência por se perceberem como incapazes de curar estes pacientes, o que aponta para uma prática curativista focada na doença. A tendência nesses casos é de um cuidado mais voltado para alívio de sintomas agudos através de intervenções medicamentosas, deixando, portanto, o sujeito em segundo plano. Essa visão não corrobora com o princípio da integralidade e de um cuidado ampliado previsto para a AB (Angelini \& Caccia-Bava, 2015).

Acontece que hoje se tem claro que práticas de cuidados nesses casos devem ser realizadas por todos os profissionais, não apenas no sentido curativista, mas numa perspectiva terapêutica, preventiva e que caminhe em prol de buscar garantir a autonomia desses sujeitos frente à produção de sua própria saúde (A. F. Silva et al., 2018).

Nesses casos, mesmos os portadores de transtorno mental grave devem ter seu espaço de cuidado e de atenção na APS. Intervenções mais intensas, como processos psicoterapêuticos e/ou intervenções medicamentosas, podem ser de responsabilidade de centros especializados como os CAPS, mas o apoio à adesão ao tratamento, os cuidados clínicos a esses usuários e a inserção na comunidade podem (e devem) ser realizados pela equipe da ESF. Também os portadores de transtornos leves, como os transtornos de ajustamento, e os portadores de transtornos mentais comuns devem ser acolhidos pelos profissionais de saúde da família com o devido suporte, incluindo a educação em saúde mental (Chiaverini, 2011).

O fato é que, mesmo compreendendo a importância da corresponsabilização, à medida que fomos nos envolvendo no trabalho e as demandas e responsabilidades foram crescendo, cada equipe passou a atuar de forma mais isolada, e cada vez mais eu me via realizando acompanhamentos clínicos individualizados sem compartilhar o cuidado em SM com as eSF. A própria questão do sigilo da clínica em psicologia me fazia questionar o que poderia ser compartilhado. Foi diante da saída de férias do outro psicólogo residente que me vi sobrecarregada. Eu tinha apenas um turno de atendimento individual e ele ficou lotado. Notei que qualquer demanda de SM que chegava às equipes era encaminhada para mim com cada vez menos compartilhamentos. Comecei a perceber como meu interesse pela SM muitas vezes também me levava a me responsabilizar pelo caso e me afastar do papel do apoio matricial.

Paralelamente, com o estreitamento dos vínculos entre os profissionais e maior convívio com questões de saúde mental do território, tema que aparecia em discussões de casos em muitas reuniões, alguns profissionais foram demonstrando interesse por maior qualificação na área. Esse aprofundamento é essencial para o trabalho na $A B$, já que a escassez disso pode trazer consequências importantes no acolhimento desses usuários no serviço, "como práticas discriminatórias e preconceituosas em relação à pessoa em sofrimento mental, além de ações moralistas, de infantilização e de normatização de condutas" (G. Silva et al., 2017).

A psicologia, na perspectiva do apoio matricial, vai ter um papel fundamental de contribuir para que os trabalhadores que se sentem despreparados possam atuar com mais segurança na construção de práticas de cuidado baseadas nas necessidades desses usuários. Por outra perspectiva, o matriciamento se torna também para nós uma oportunidade de compreender melhor quais as dificuldades e potencialidades de outras áreas da saúde diante da SM (G. Silva et al., 2017). Existem possibilidades infinitas frente a essa perspectiva de trabalho conjunto e com abertura para trocas, especialmente quando as relações entre as diferentes categorias se dão de forma horizontal. 
Dialogando com outros serviços da RAPS percebi que a solução não era encaminhá-los para atenção especializada, afinal muitos encaminhamentos não estavam sendo acolhidos lá. Havia uma sobrecarga para o número reduzido de psicólogas(os) no município. Então surgiu a grande questão: Como garantir um acompanhamento dos casos do território que tinham o perfil para $A B$, sem reproduzir um padrão meramente clínico? Essa resposta não está dada, ela precisa ser construída a partir de cada equipe, demandava criação de novas estratégias e ampliação do cuidado. Resolvi então levar meu desabafo para uma reunião de NASF, e a partir daí começamos a discutir possíveis mudanças nas formas de se produzir cuidado que abrissem espaço para a transdisciplinaridade. A sobrecarga me provocou o incomodo necessário para criar algo, e foi a partir daí que surgiu a ideia deste grupo voltado à SM, e que mais tarde foi nomeado por seus membros (profissionais e usuários) como "Bem Viver". A proposta do Bem Viver foi construída e realizada em conjunto com uma eSF e outo psicólogo do NASF que demonstravam interesse pelo tema, a ideia era criar um espaço de fala e escuta onde fosse possível produzir e disseminar diálogos, trocas e afetações, e com isso gerar efeitos terapêuticos e matriciais.

Grupos são em si ferramentas de cuidado que permitem acolher a integralidade dos sujeitos, na medida em que eles têm liberdade para falar de si e de seus sofrimentos de uma maneira mais informal. Eles têm o potencial também de possibilitar uma horizontalidade e continuidade do cuidado, já que os encontros são periódicos e os vínculos podem ser estreitados ao longo do tempo (Ministério da Saúde, 2010). Para isso não basta simplesmente que o grupo exista, mas que os profissionais não adotem uma posição de únicos detentores do saber, e não utilizem desse espaço para disseminar um suposto ideal normalizador, promovendo a institucionalização e o sufocamento de subjetividades. Ao contrário disso, para promoção de cuidado e por sua vez de saúde, é importante que ele seja um espaço que propicie a expressão das singularidades, a integração e socialização, especialmente das pessoas mais diversas que vivem numa mesma comunidade e que podem formar entre si suas próprias redes de apoio (G. Silva et al., 2017).
Como este grupo foi uma alternativa de ampliação do cuidado e corresponsabilização, sua ideia passou a ser discutida entre todos os profissionais da USF, foi pauta em reunião da eSF, de NASF e de unidade. Era unanimidade o desejo de que o grupo não fosse delimitado para o território apenas da equipe responsável, mas de toda USF. Discutimos alguns detalhes sobre como garantir espaço para isso, tanto na agenda como um espaço físico que permitisse privacidade. A discussão foi levada também para o matriciamento intersetorial com o CAPS as e o Consultório de Rua. Neste espaço foi esclarecido o público-alvo, além de algumas dicas de manejo, respeito a autonomia do sujeito frente a seu processo de saúde e atenção com a integralidade. A cada reunião o grupo ia tomando forma e íamos nos empolgando, o planejamento conjunto nos desafiava a pensar e repensar, permitia que outras pessoas que não estavam diretamente envolvidas atentassem mais para as questões de SM no território e que todos nós víssemos que a $A B$ pode fazer mais por esses usuários.

Os ACS se tornaram essenciais no quesito de identificar e promover nossa aproximação, por meio de visitas domiciliares, com os usuários que tinham o perfil para tal. Isto é, pessoas com transtornos mentais leves ou moderados, ou transtornos psicóticos estabilizados, e ainda pessoas que estivessem vivenciando outras situações e sofrimento psicológico e emocional que não tinham necessariamente um diagnóstico.

Havia uma preocupação e insegurança entre alguns dos profissionais em relação a doença mental grave, especialmente os casos de psicose. Ouvimos inclusive questionamentos sobre se isso não seria papel dos CAPS. Esclarecemos que o foco era voltado para pacientes de SM previstos para serem acompanhados na $A B$; mas que a depender de cada sujeito e gravidade do caso, outras questões de sofrimento psíquico também seriam acolhidas. E aí transformamos diagnósticos em nomes, falamos sobre pessoas da comunidade que já conhecíamos, que já usavam o serviço e que tinham diagnósticos de esquizofrenia por exemplo, e como seria viável e saudável para elas um espaço como esse. Não sei se existe melhor forma de superar alguns estigmas da doença mental do que poder ver os sujeitos por trás dos diagnósticos. 
O estigma da SM, ou melhor, da doença mental acompanha esses sujeitos há muitos anos, colando-os a uma ideia de periculosidade, imprevisibilidade, alienação e incapacidade (Angelini \& Caccia-Bava, 2015). Essa visão subentende a existência de um padrão de normalidade, no qual tudo que se difere dele é marginalizado e excluído num processo de higienização social, e isso impacta até hoje a forma como esses usuários são acolhidos nos serviços de saúde (A. F. Silva et al., 2018). Quando é a doença que fica em evidência, abre-se um abismo entre o profissional e a pessoa que adoece. Apenas quando nos dispomos a conhecer e escutar os sujeitos é que se pode, junto com ele, construir novas formas de promoção de saúde e melhoria de suas condições de vida

\section{O desenvolvimento do Bem Viver}

O primeiro dia do Bem Viver foi vivenciado com ansiedade pelos profissionais, algumas dúvidas pairavam em nossas cabeças: será que eles viriam? Será que vão se sentir à vontade? Será que conseguiremos nos vincular? O grupo iniciou com apenas 3 usuários. A programação envolvia um momento para explicar a proposta do grupo, em seguida seria realizada uma dinâmica de apresentação e um relaxamento e, no encerramento, o médico tocaria uma música. O primeiro encontro visava o estabelecimento e fortalecimento de vínculo, além de um "quebra gelo" para que pudessem aos poucos irem se sentindo mais à vontade. A dinâmica de apresentação extrapolou o tempo imaginado, e tomou todo nosso tempo do grupo, pois os presentes demonstraram grande demanda de fala. Isso evidenciou a importância daqueles usuários serem escutados e acolhidos. Era o início de uma vinculação que foi se estreitando à medida que eles retornavam a cada semana. A música foi cantada por todos em conjunto, e acabamos decidindo que está seria uma prática semanal. Ao final do grupo os profissionais se reuniram para avaliar o momento, discutimos como pode ser difícil para algumas pessoas se desafiarem a abrir suas fragilidades e falar de suas dores. Discutimos também as potencialidades daquele espaço diante do saldo positivo que tivemos com os presentes. Decidimos intensificar o processo de busca ativa (visitas domiciliares a pacientes identificados pelos ACS) e divulgação do grupo (pelos profissionais de saúde nas consultas e outros grupos da USF).
Aos poucos o Bem Viver foi crescendo, a ponto de termos que limitar a média de 10 a 12 participantes. Chegou a se pensar que caso a demanda superasse esse número, faríamos dois momentos de grupo, porém não foi necessário.

No início as(os) psicólogas(os) acabaram assumindo a frente dos planejamentos e coordenação do grupo; no entanto isso foi sendo modificado ao longo do tempo, à medida que os outros profissionais e os usuários iam se sentindo pertencentes, vinculados e mais familiarizados com as questões de SM, a corresponsabilização fluiu.

O grupo sempre era iniciado com um momento de apresentação, caso houvesse novos membros, onde podíamos nos conhecer, estreitar vínculos e confirmar a demanda. Era também um momento de "Como você está? Como passou a semana?". Em seguida, eram realizadas dinâmicas ou um momento de apreciação de alguma produção artística (pinturas, poemas, trechos de filmes, livros, desenhos, músicas etc.), que com o tempo passaram a ser trazidas ou até produzidas pelos próprios usuários. Descobrimos que tínhamos inclusive um desenhista no grupo. A ideia é que esses disparadores abrissem espaço para que eles pudessem falar de suas experiências, suas dores e da forma como vinham aprendendo a lidar com as dificuldades, isto é, que abríssemos um espaço para que pudessem expressar através da palavra o que é difícil de ser dito. Bondía (2002) destaca que as palavras são importantes mecanismos de subjetivação, já que possibilitam a produção de sentidos e criação de realidades.

Eu creio no poder das palavras, na força das palavras, creio que fazemos coisas com as palavras e, também,

que as palavras fazem coisas conosco. As palavras determinam nosso pensamento porque não pensamos com pensamentos, mas com palavras, não pensamos a partir de uma suposta genialidade ou inteligência, mas a partir de nossas palavras. E pensar não é somente "raciocinar" ou "calcular" ou "argumentar", como nos tem sido ensinado algumas vezes, mas é sobretudo dar sentido ao que somos e ao que nos acontece. E isto,

o sentido ou o sem-sentido, é algo que tem a ver com as palavras. E, portanto, também tem a ver com as palavras o modo como nos colocamos diante de nós mesmos, diante dos outros e diante do mundo em que vivemos. E o modo como agimos em relação a tudo isso. (Bondía, 2002, p. 21). 
Para que estas afetações, elaborações e transformações sejam possíveis, é importante que as pessoas possam sentir que aquele grupo é um lugar seguro para experimentar o viver (Ministério da Saúde, 2010), que suas questões serão acolhidas sem julgamentos, sem repressão, e com um pacto de sigilo estabelecido.

No final de cada grupo fazíamos um momento de avaliação do dia junto aos usuários e ouvíamos suas opiniões e sugestões. Percebemos com o tempo da existência de um espaço junto equipe após cada grupo para avaliarmos o dia, era um momento de matriciamento, onde se podia perceber as dificuldades de cada um em lidar com questões de sofrimento que apareciam. "Sim, dificuldade de sustentar o choro do outro, sendo que aquele era o momento que o outro tinha para chorar. Dificuldade de não ter uma resposta pronta ou uma orientação/conseIho para dar, o que apontava para aprender sobre construir estratégias junto ao paciente." (Cangussu, 2020, p. 18). Dificuldade até de querer fazer mais, e ter que lidar com os limites da assistência, e com a autonomia de cada sujeito frente ao seu processo de saúde/doença. Dificuldades até em simplesmente escutar, sem cortar, sem direcionar, e ao mesmo tempo garantindo que não houvesse um único paciente protagonizando toda a discussão. Como era interessante esse momento de troca, de perceber como o grupo vinha sensibilizando, nós profissionais em nossa atuação; perceber a potencialidade do apoio matricial na realidade e o papel da própria $A B$ frente à $S M$ e frente a RAS.

Era nessas horas que percebia que a verdadeira experiência estava acontecendo. Bondía (2002) destaca que vivemos em um mundo onde o excesso de informação, a imediaticidade de formar uma opinião e a aceleração do tempo que se perde em si mesmo, dificultam que a gente possa se permitir viver a experiência. O Bem Viver se tornou um espaço onde podíamos nos permitir aprender a viver a experiência a cada dia, aprender a nos questionar sobre nossos conceitos e opiniões já pré-estabelecidas, sermos surpreendidos pelas nossas dificuldades em lidar com a dor do outro, atentar para as diferenças de cada um, podíamos sair do automatismo e olhar, pensar, escutar, sentir, podíamos nos desconstruir e nos reconstruir sem pressa ou exigências.
Volta e meia surgiam espontaneamente alguns feedbacks positivos, eles nos estimulavam e nos tranquilizavam de que estávamos no caminho certo. "Estar no caminho certo" aqui não significa não ter dificuldades ou não cometer erros, mas ter abertura para escuta, flexibilidade para transformar aquele espaço e dinamicidade frente ao coletivo e à vivacidade das relações.

Tínhamos o privilégio de ter ao menos uma ACS presente no grupo, e ela era aberta a escutar e sensível às questões abordadas. Algumas histórias trazidas vinham com a referência a esta profissional: "ela sabe o que eu passei, ela acompanhou". Havia uma identificação com aquela figura da comunidade que vivia ali há anos e representava a saúde, e que acabava por estreitar o vínculo desses usuários com os outros profissionais. "A participação de agentes de saúde nas equipes de coordenação de grupos pode facilitar o conhecimento dos usuários do grupo, a história daquela comunidade e o modo como eles lidam com as relações na vida." (Ministério da Saúde, 2010, p. 114).

Com o tempo os usuários começaram a trazer outros participantes para o grupo e passaram também a comparecer em outros grupos, enfim, eles estavam estreitando os laços com a USF e, portanto, com sua própria saúde. As músicas finais se tornaram tradição, elas despertavam coros, risos, choros, e até cantorias mais exageradas. Inicialmente tendíamos a pensar em músicas que traziam como temas as emoções, o cuidado, o bem-estar etc., mas em algumas sessões tivemos a presença de uma usuária (já acompanhada pelo (APS) que tem um diagnóstico de esquizofrenia e uma risada contagiante, e que se pode dizer que era movida pela música. Ela acabava por nos incentivar a relembrar e cantar em roda várias canções, modinhas carnavalescas, sambas etc. Ela conseguiu nos fazer levantar, dançar e mostrar que a música em si nos atravessa e nos afeta, independente do tema que aborde. R. S. Silva \& Moraes (2007) destacam esse poder da música de permitir a coexistência de uma diversidade de sons, ritmos, histórias e subjetividades, e como produzem transversalidade, multiplicidade, movimentos e transformações.

A dinâmica da USF acabava por trazer ainda outras dificuldades: dias em que o planejamento não ocorria e acabávamos criando algo por telefone nos finais 
de semana; profissionais que tinham que se ausentar em dias que iam coordenar o grupo, e outros acabaram assumindo a responsabilidade em seu lugar; a forma diferente de cada uma(um) das(os) psicólogas(os) de atuar que mudava um pouco a estrutura do grupo, afinal cada sujeito diferente presente tende a modificar o espaço. Mas isso acabava por potencializar ainda mais o aprendizado em lidar com o inesperado. Lembro-me de um desses planejamentos às pressas que elaborei com a enfermeira remotamente numa noite de domingo, e que não conseguimos pensar em que musica incluir e não achávamos que haveria tempo do médico aprender àquela altura. No dia seguinte o médico chegou com o violão e já tinha uma música em mente, não precisava que alguém pedisse, todos nos sentíamos responsáveis.

Por vezes alguns usuários membros vinham justificar sua ausência, demonstrando um compromisso e vínculo, os motivos eram variados: de mudança de residência para outro território a sentir-se melhor, ter conseguido um emprego e seguido a vida. A configuração do grupo era fluída e ele ia ganhando novas características a cada pessoa a mais ou a menos.

Aos poucos fomos aprendendo a acolher singularidades e nos deixando ser afetados por elas. De acordo com Paulo Amarante, citado por Luchmann e Rodrigues (2007), "loucura se refere a esta experiência humana de estar no mundo de uma forma diversa daquela que o homem, ideológica e idealisticamente, considera como normal. E louco é o sujeito destas vivências ("erlebenis") e destas experiências.". Ao refletir sobre essa definição e esta experiência conjuntamente, fica uma grande questão: será que podemos todos sermos mais loucos as vezes? Essa pergunta vem com todo o reconhecimento do sofrimento daqueles que realmente adoecem psiquicamente e sabendo que nenhum de nós está livre disso, mas compreendendo que para construir novas formas de saber e agir no mundo diante de pessoas tão singulares e complexas, precisamos transpor a normalidade ideológica e idealística posta pelo homem e entender que loucura e saúde podem se relacionar. Produzir transdisciplinaridade é sair dessa atuação automática, estabelecer vínculos horizontais com os usuários e se permitir se transformar nesse processo.
Por fim, com aproximadamente o período de 6 meses em que iniciamos o bem viver, o programa de residência optou por sair do território, o que acabou por encerrar o grupo. A saída desta USF e do município foi um processo de mudança muito difícil para todos, e especialmente um processo de despedidas de projetos, de espaços de cuidados, de laços, de sujeitos. Elaboramos uma carta de despedida que foi lida e escutada com muito pesar. Tínhamos planejado um amigo secreto e confraternização de fim de ano coincidentemente para este dia, o que nos possibilitou um fechamento daquele espaço e a clareza de como havia afeto naquelas relações. Como mensagem final destacamos como era importante que os usuários entre si mantivessem aquele vínculo, e de criarem em suas vidas espaços em que pudessem promover SM. Sugerimos também que fosse usado do controle social para pedir a recriação daquele espaço com os profissionais que ficassem. E assim nossas vidas se seguiram, separados e marcados por essa parte da nossa história em que vidas se cruzaram.

Os feedbacks que recebemos demonstravam que 0 grupo tinha promovido saúde mental, as pessoas se sentiam bem em estar ali, trouxeram como acabavam marcando encontros fora de lá, como alguns criaram amizades com quem podiam conversar, como outros se sentiam valorizados pelas contribuições que traziam e acolhidos por todos. Quanto aos profissionais, percebo que quanto mais se passou a falar e abrir espaço para a SM, mais pessoas me procuravam querendo discutir os casos, e inclusive considerando que determinado caso poderia ser cuidado na AB. ACS vinham conversar sobre alguns usuários, profissionais pediam para participar um dia para conhecer o Bem Viver, e nós aprendemos a escutar e acolher a dor do outro um pouco mais.

\section{Considerações Finais}

Após décadas nas quais a doença mental era tomada como um carimbo que definia pessoas como alienadas, incapazes e destituídas de suas subjetividades, a SM hoje e toda mudança em seu modelo 
de cuidado, vem transformar relações e se propor a enxergar sujeitos. Essa mudança de paradigma não é fácil, na medida que exige o abandono de alguns estigmas enraizados na sociedade e um despir-se de uma posição narcísica e hierarquizada de sabedoria. Torna-se ainda mais difícil diante de profissões que não abordam a SM em suas formações. As equipes mínimas chegam à $A B$ e são inundadas por situações de sofrimento psíquico nas quais, muitas vezes, não se sentem seguras de acolher e se responsabilizar. Os profissionais do NASF por sua vez, também formados a partir de um sistema cartesiano no qual cada um cuida de uma parte do sujeito, ainda estão aprendendo a realizar o apoio matricial, e mesmo aqueles que se engajam em valorizar e difundir a prática esta prática, compreendendo todo seu potencial transformador, esbarram na falta de financiamento específico que ameaça até a manutenção da existência do próprio NASF. A lógica da transdisciplinaridade e a próprio cuidado do sujeito em sua integralidade ficam ameaçados em lugar de cumprir protocolos e comprovar quantitativamente uma produtividade.

Esta proposta de um cuidado longitudinal que respeita a integralidade e autonomia do sujeito, exige um processo de formação de vínculos e abertura para escuta, afinal não existe conhecimento teórico que nos permita a saber mais do outro do que ele mesmo. $\mathrm{O}$ trabalho em grupo tem como potencial permitir uma aproximação maior entre os usuários e profissionais a longo prazo, assim como também permite que todos possam se expressar de maneira mais livre e informal, contar de seus diferentes modos de viver, espelhar-se em como o outro lida com seus problemas, além de possibilitar choros, risos, cantos e encantos.

O Bem Viver foi construído a partir dessa perspectiva, como um meio de ampliar o cuidado dos usuários com questões de SM daquele território. Não foi apenas um procedimento, atendimento ou medicamento ofertado, mas uma experiência que passou a fazer parte da vida de todos os envolvidos, afetando-nos de uma forma transformadora. Não era a doença mental que estava sendo atenuada, ou, de uma forma muito utópica, curada; era "fulana" que estava passando por tal dificuldade, era "cicrana" que tinha determinadas cicatrizes que lhe paralisavam, eram pessoas que sofriam e demandavam um acolhimento.

Se abrir para escutar a dor do outro não é tarefa fácil e exige sim ser aprendido, ser exercitado, sermos sensibilizado. Mas como ensinar/aprender isso se não for vivenciando? Como promover o matriciamento se não for se abrindo para uma experiência de troca? Todos, usuários e profissionais, tínhamos ali esta oportunidade de vivenciar e construir juntos um cuidado diferenciado. Diferenciado não por ser melhor ou pior, mas porque advinha daquelas relações, foi construído por aquelas pessoas e para aquelas pessoas.

$A A B$ é um serviço fundamental na estruturação da RAPS, e tem um potencial inenarrável diante da SM. O que falta, muitas vezes é se permitir criar possibilidades que saiam de um padrão biomédico pré-estabelecido, é sair do estigma para cuidar de sujeitos, mesmo que isso envolva enfrentar seus medos, é superar o meramente procedimental para ser afetado pelas vivências do outro.

\section{Agradecimentos}

Agradeço à Secretaria de Saúde de Lauro de Freitas do ano de 2018. Agradeço também à FESFSUS e todo o corpo pedagógico e equipe de residentes do período de 2018 a 2020, à FIOCRUZ/BA e à fonte pagadora da bolsa de residência.

\section{Contribuições dos autores}

Cangussu, Y. E. S. participou da criação, delineamento, análise e redação do artigo científico. Guedes, L. F. participou do delineamento, orientação e revisão do artigo científico.

\section{Conflitos de interesses}

Nenhum conflito financeiro, legal ou político envolvendo terceiros (governo, empresas e fundações privadas etc.) foi declarado para nenhum aspecto do trabalho submetido (incluindo, mas não se limitando a subvenções e financiamentos, participação em conselho consultivo, desenho de estudo, preparação de manuscrito, análise estatística etc.). 


\section{Referências}

Almeida, D. R., Soares, J. N. C., Dias, M. G., Rocha, F. C., Andrade Neto, G. R., \& Andrade, D. L. B. (2020). O cuidado aos portadores de sofrimento mental na atenção primária: uma prática interdisciplinar e multiprofissional. Revista de Pesquisa Cuidado é Fundamental Online, 12, 420-425. https://doi.org/10.9789/21755361.rpcfo.v12.8388

Amarante, P. (Coord.). (1995). Loucos pela vida: trajetória da reforma psiquiátrica no Brasil. Fiocruz.

Angelini, C. R., \& Caccia-Bava, M. C. G. G. (2015). “A gente sente que precisa e pode...": os desafios para a inclusão da saúde mental na atenção básica. Revista Brasileira de Medicina de Família e Comunidade, 10(36), 1-9. http://dx.doi.org/10.5712/rbmfc10(36)1033

Bondía, J. L. (2002). Notas sobre a experiência e o saber de experiência. Revista Brasileira de Educação, 10(19), 20-28. https:// doi.org/10.1590/S1413-24782002000100003

Cangussu, Y. E. S. (2020). Caminhando pela saúde da família e redescobrindo a saúde mental: memorial de uma psicóloga na Residência Multiprofissional em Saúde da Família [monografia, Fundação Estatal Saúde da Família e Fundação Osvaldo Cruz]. ARCA: Repositório Institucional da Fiocruz. https://www. arca.fiocruz.br/bitstream/icict/48496/2/TCR\%20YANNA\%20 IMBIRU\%C3\%87U\%202020.pdf

Chiaverini, D. H. (Org.). (2011). Guia prático de matriciamento em saúde. Editora UERJ.

Gerhardt, T. E., \& Silveira, D. T. (2009). Métodos de pesquisa. Plageder.

Instituto Brasileiro de Geografia e Estatística. (2010). Censo Demográfico. https://cidades.ibge.gov.br/brasil/ba/lauro-defreitas/panorama

Klein, A. P., \& d'Oliveira, A. F. (2017). O “cabo de força” da assistência: Concepção e prática de psicólogos sobre o apoio matricial no núcleo de apoio à saúde da família. Cadernos de Saúde Pública, 33(1), e00158815. https://doi.org/10.1590/0102$\underline{311 \times 00158815}$

Lei $n^{\circ}$ 10.216, de 6 de abril de 2001. (2001). Dispõe sobre a proteção e os direitos das pessoas portadoras de transtornos mentais e redireciona o modelo assistencial em saúde mental. Diário Oficial da União, Brasília, DF, 06 abr. 2001,

Lei $n^{\circ} 11.129$, de 30 de junho de 2005. (2005). Institui o Programa Nacional de Inclusão de Jovens - ProJovem; cria o Conselho Nacional da Juventude - CNJ e a Secretaria Nacional de Juventude; altera as Leis $n^{\circ} \mathrm{s} 10.683$, de 28 de maio de 2003, e 10.429, de 24 de abril de 2002; e dá outras providências. https://codigos.vlex. com.br/vid/lei-n-11-129-655387705
Luchmann, L. H. H., \& Rodrigues, J. (2007). O Movimento

Antimanicomial no Brasil. Ciência \& Saúde Coletiva, 12(2), 399-407. https://dx.doi.org/10.1590/S1413-81232007000200016

Melo, E. A., Mendonça, M. H. M., Oliveira, J. R., \& Andrade, G. C. L. (2018). Mudanças na política nacional de atenção básica: Entre retrocessos e desafios. Saúde em Debate, 42(spe1), 38-51. https:// doi.org/10.1590/0103-11042018s103

Ministério da Saúde. (2012). Política Nacional de Atenção Básica. Departamento de Atenção Básica, Secretaria de Atenção à Saúde. https://aps.saude.gov.br/biblioteca/visualizar/MTE4OA==

Ministério da Saúde. (2013). Cadernos de atenção básica: Saúde mental. Departamento de Atenção Básica, Secretaria de Atenção à Saúde. https://pesquisa.bvsalud.org/bvsms/resource/pt/mis36251

Ministério da Saúde. (2010). Cadernos HumanizaSUS. Secretaria de Atenção à Saúde. https://bvsms.saude.gov.br/bvs/publicacoes/ cadernos_humanizaSUS.pdf

Nascimento M. L., \& Lemos F. C. S. (2020). A pesquisa-intervenção em psicologia: Os usos do diário de campo. Barbarói: Revista do Departamento de Ciências Humanas, 57, 239-253. https://doi. org/10.17058/barbaroi.v0i57.14675

Nogueira, F. J. S., \& Brito, F. M. G. (2017). Diálogos entre saúde mental e atenção básica: Relato de experiência do pet-saúde no município de Parnaíba-PI. Pesquisas e Práticas Psicossociais, 12(2), 374-387. http://pepsic.bvsalud.org/scielo.php?\%20script=sci arttext\&pid=S1809-89082017000200010\&lng=pt\&nrm=isso

Portaria $n^{\circ}$ 154, de 24 de janeiro de 2008. (2008). Cria os núcleos de apoio à saúde da família - NASF. https://bvsms.saude.gov.br/ bvs/saudelegis/gm/2008/prt0154_24_01_2008.html

Portaria $n^{\circ}$ 2.436, de 21 de setembro de 2017. (2017). Aprova a Política Nacional de Atenção Básica, estabelecendo a revisão de diretrizes para a organização da Atenção Básica, no âmbito do Sistema Único de Saúde (SUS). https://bvsms.saude.gov.br/bvs/ saudelegis/gm/2017/prt2436_22_09_2017.html

Portaria $n^{\circ}$ 3.088, de 23 de dezembro de 2011. (2011). Institui a Rede de Atenção Psicossocial para pessoas com sofrimento ou transtorno mental e com necessidades decorrentes do uso de crack, álcool e outras drogas, no âmbito do Sistema Único de Saúde (SUS). http://bvsms.saude.gov.br/bvs/saudelegis/gm/2011/ prt3088 23122011 rep.html

Ramos, P. F., \& Pio, D. A. M. (2010). Construção de um projeto de cuidado em saúde mental na atenção básica. Psicologia: Ciência e Profissão, 30(1), 212-223. https://doi.org/10.1590/S141498932010000100016 
Reis, S., \& Meneses, S. (12 de fevereiro, 2020). Novo financiamento da atenção básica: Possíveis impactos sobre o NASF-AB. Centro Brasileiro de Estudos de Saúde. https://cebes.org.br/ novo-financiamento-da-atencao-basica-impactos-sobre-o-nasf$\mathrm{ab} / 21242 /$

Reyner, G. (05 de agosto, 2019). Com 75\% de cobertura na Atenção Básica, índice deve atingir $100 \%$ até final do ano em Lauro de Freitas. https://www.laurodefreitas.ba.gov.br/2019/ noticias/com-75-de-cobertura-na-atencao-basica-indice-deveatingir-100-ate-final-do-ano-em-lauro-de-freitas/1246

Silva, A. F., Florencio, R. M. S., Queiroz, A. M., Santos, E. M., Carvalho, L. C., Pereira, A., \& Lima, V. L. A. (2018). Acolhimento à pessoa em sofrimento mental na Atenção Básica. Revista de Enfermagem UFPE Online, 12(9), 2459-2469. https://doi. org/10.5205/1981-8963-v12i9a234705p2459-2469-2018
Silva, G., Iglesias, A., Dalbello-Araujo, M., \& Badaró-Moreira, M. I. (2017). Práticas de cuidado integral às pessoas em sofrimento mental na atenção básica. Psicologia: Ciência e Profissão, 37(2), 404-417. https://doi.org/10.1590/1982-3703001452015

Silva, M. M. S., Dias, M. S. A., Saraiva, M. J. G., Silva M. R. F., \& Vasconcelos, M. I. O. (2015). A produção de tecnologias enquanto efetividade da residência multiprofissional em saúde da família. In M. S. A. Dias, M. M. S. Silva, F. L. Souza, A. K. S. Gadelha, \& E. A. S. Alves (Orgs.), Tecnologias leves em saúde: Saberes e práticas da residência multiprofissional na estratégia saúde da família (pp. 13-37). Rede UNIDA.

Silva, R. S., \& Moraes, M. (2007). Musicoterapia e saúde mental: Relato de uma experimentação rizomática. Revista Psico (Porto Alegre), 38(2), 139-147. https://pesquisa.bvsalud.org/portal/ resource/pt/lil-522149 